infiltrando o miocárdio dos ventrículos direito e esquerdo. No exame histopatológico pôdese constatar infiltrados de células mononucleares monocitóides em diversos órgãos, bem como escassez de eritrócitos nos vasos sangüineos. Os achados do hemograma, do exame de medula óssea, em conjunto com aqueles da necropsia e do histopatológico, permitiram concluir o diagnóstico de leucemia monocítica aguda.

\title{
95 - Defeitos congênitos do palato em cães. Relato de três casos
}

Hette K.'; Rahal S.C.'

Lopes, F.M. '; Leon Roman, M.A.';

Ferro, D.G. ${ }^{2}$; Correa, H.L. ${ }^{2}$;

Venturini, M.A.F.A. ${ }^{3}$; Gioso, M.A. ${ }^{4}$
1- Faculdade de Medicina Veterinária e Zootecnia da Universidade Estadual Paulista, Campus de Botucatu, Botucatu-SP

Os defeitos congênitos do palato sào pouco freqüentes em càes, sendo os braquicefálicos os mais predispostos. Uma fenda palatina primária consiste em qualquer fenda cranial ao forame incisivo e envolvendo o lábio, ao passo que a fenda secundária ocorre caudal ao forame incisivo. $\mathrm{O}$ objetivo do trabalho é relatar três casos de cães com fendas palatinas congênitas, que foram encaminhados ao hospital veterinário da Unesp, Campus de Botucatu. Caso 1 - cadela da raça Bulldog, dois meses de idade, apresentando lábio fendido e fenda na linha média dos palatos duro e mole. Caso 2 - cadela da raça Fox Terrier, dois meses de idade, com fenda unilateral do palato mole. Caso 3 - cão da raça Poodle, macho, quatro meses e três semanas de idade, com fenda na linha média dos palatos duro e mole. $\mathrm{O}$ método de tratamento empregado nos casos 1 e 3 foi à técnica de retalho duplo com reposição medial $\mathrm{e}$ incisòes de alívio de tensão. Este foi de fácil execução e apresentou bons resultados em ambos os animais. No caso 3, utilizou-se o método de sutura em duas camadas, que se mostrou inadequado. As fendas palatinas, especialmente as do palato duro e mole, são deformidades que exigem correçào cirúrgica por acarretarem risco de vida. A identificaçào precoce da precoce favorece a instituição de medidas terapêuticas e de suporte nutricional. Por causa da possibilidade de envolvimento hereditário, preconiza-se a não utilização do animal para fins reprodutivos.

\section{6 - Fraturas mandibulares em cães. Estudo retrospectivo}

1-Laboratório de Odontologia Comparada da Faculdade de Medicina Veterinária e Zootecnia da Universidade de São Paulo, São Paulo-SP

2- Pós-graduação da Faculdade de Medicina Veterinária e Zootecnia da Universidade de São Paulo, São Paulo-SP

3- Médica Veterinária Autonoma

4- Departamento de Cirurgia da Faculdade de Medicina Veterinária e Zootecnia da Universidade de São Paulo, São Paulo-SP

As fraturas mandibulares são consideradas afecções pouco freqüentes em cães, decorrentes, na maior parte dos casos, a traumatismos. As fraturas patológicas, decorrentes principalmente a periodontites e neoplasias, ocorrem com maior frequêencia em càes idosos e de pequeno porte, especialmente após brigas ou iatrogenicamente, durante a exodontia. Existem poucos estudos sobre a prevalência de fraturas mandibulares nesta espécie, especialmente quanto a: etiologia, distribuição etária e localização da fratura; nào havendo trabalhos semelhantes no Brasil. Estes fatores são considerados fundamentais para a determinação do tipo e padrão da lesão, do prognóstico e do método de tratamento da fratura. Assim, o estabelecimento desses fatores e o conhecimento de suas características e prevalências são de grande valia para a rotina clínica e cirúrgica do profissional médico veterinário. As fichas clínicas de 3666 animais da espécie canina atendidos entre agosto de 1994 e abril de 2003 no ODONTOVET 
- Centro Odontológico Veterinário foram revisadas, constatando-se a ocorrência de 129 focos de fratura mandibular em 91 cães $(2,4 \%)$. Os traumatismos constituíram o principal fator etiológico, representados, principalmente, por brigas com outros animais $(40,2 \%)$ e atropelamentos (13\%); em $25 \%$ dos casos a origem das fraturas não pôde ser determinada. As fraturas consideradas patológicas corresponderam a $14,1 \%$ do total; em um caso a fratura foi iatrogênica. Pôde-se notar o acometimento significativo de diferentes faixas etárias, mais prevalente em animais com idade em torno de um ano e de 8 anos de idade. Cerca de $70 \%$ dos animais acometidos no estudo foram considerados de pequeno porte, sendo a raça Poodle a mais prevalente, representando $31,8 \%$ do total. Com relação à distribuiçào sexual, as fraturas mandibulares foram diagnosticadas em 63 machos $(68,1 \%)$ e 29 fêmeas $(31,9 \%)$. Em apenas 3,3\% dos casos houve lesão concomitante em maxila. A região molar constituiu o principal foco de fratura mandibular nesta espécie, correspondendo a $46,5 \%$, seguida pela regiào de sínfise e parassínfise mentoniana $(31 \%)$, região pré-molar $(17,8 \%)$, processo angular $(3,9 \%)$ e ramo vertical $(0,8 \%)$. Pôde-se concluir que as fraturas mandibulares apresentam discreta prevalência em cães, acometendo, geralmente animais de pequeno porte. Os principais fatores etiológicos envolvidos nestes casos são brigas com outros animais e atropelamentos por automóveis, sendo relevante a ocorrência de fraturas patológicas na espécie. O principal foco de fratura mandibular em cães corresponde à região molar, principalmente próximo ao dente $1^{\circ}$ molar; na região rostral o principal foco envolve a regiào do dente canino.

\section{7 - Artrite séptica em cão. Relato de caso}

Champion, T. ${ }^{4}$; Sincero, P.C. ${ }^{2}$; Locatelli-Dittrich, R.'; Franco, M.B. ${ }^{2}$; Sprea, G. ${ }^{3}$; Baudi, D.L.K. ${ }^{3}$; Silva, G.B. ${ }^{4}$
1- MV, DR., Professor do Departamento de Medicina Veterinária da Universidade Federal do Paraná, Curitiba-PR

2- MV, MS, Professor do Departamento de Medicina Veterinária da Universidade Federal do Paraná, Curitiba-PR

3- MV, Mestranda do programa de Pós-graduação da Universidade Federal do Paraná, Curitiba-PR

4- Médica Veterinária do Hospital Veterinário da Universidade Federal do Paraná, Curitiba-PR

A artrite séptica é uma artropatia inflamatória, resultante de contaminação por via hematógena ou através de inoculaçào direta de um microrganismo. Os agentes infecciosos mais implicados no cão são Staphilococcus spp., Streptococcus spp., Escherichia coli, e em gatos Pasteurella spp. Além de bactérias, micoplasma, riquétsias, fungos e vírus também podem causar artrite séptica. A doença acomete principalmente càes, machos e de grande porte. Os sinais clínicos incluem claudicaçào, articulaçòes dolorosas, quentes e com efusão articular além de sinais sistêmicos, como febre, letargia e anorexia. A análise macroscópica do líquido sinovial revela evidências de doença articular, seja pela coloraçào, volume, coagulação ou viscosidade do líquido. $\mathrm{O}$ líquido sinovial normal possui população mista, inferior a 3.000 células $/ \mathrm{ml}$, com predominância de células mononucleares e os neutrófilos constituem menos de $12 \%$ do total. Em líquido sinovial de animais com artrite séptica, os neutrófilos representam maioria (acima de 90\%), podendo-se apresentar degranulados, tóxicos ou degenerados, havendo ainda elevaçào do nível de proteinas para valores acima de $2,5 \mathrm{~g} / \mathrm{dl}$. Animais com artrite imunomediada, por sua vez, podem ou não apresentar neutrofilia no líquido sinovial e neste caso, os neutrófilos possuem aparência normal. O aumento de células nucleadas mononucleares ocorre em várias doenças articulares crônicas e em articulações que tenham sofrido traumas ou alterações degenerativas. O objetivo deste trabalho é relatar a utilização da artrocentese e análise do liquido sinovial como diagnóstico diferencial de algumas artropatias, enfatizando que a cultura do líquido sinovial negativa nào descarta a artrite séptica como diagnóstico. O presente trabalho descreve um cào da raça Chow Chow, atendido no HV-UFPR que apresentava hiporexia e claudicação com o membro pélvico esquerdo há 10 dias. $\mathrm{O}$ animal já havia sido medicado com Carprofeno, porém além de não apresentar remissão dos sinais, ocorreu envolvimento de outras articulaçôes. Ao exame físico foram observadas febre, crepitação e sensibilidade dolorosa à palpação das articulações carporadial, fêmuro-tibio-patelar e coxo-femoral esquerdas. O hemograma revelou leucocitose 